\title{
ALBERT THEILE, MEDIADOR PIONERO. LOS EXILIADOS ALEMANES EN AMÉRICA LATINA Y LA PUBLICACIÓN DE LITERATURA LATINOAMERICANA EN EL MUNDO GERMANOHABLANTE EN EL PERÍODO DE POSGUERRA
}

\author{
Jorge J. Locane \\ Universidad de Colonia \\ Colonia, Alemania \\ jjlocane@gmail.com
}

La (no) circulación internacional de literatura está condicionada en gran medida y dependiendo del contexto específico por factores extraliterarios que exceden o subordinan la valoración estética. Según propone Gisèle Sapiro, estos factores pertenecen a cuatro órdenes: al político, al cultural, al económico y al social. La colección "Obras representativas", promovida por la UNESCO desde 1948, que reúne literaturas del mundo en traducción, responde, por ejemplo, a principios dinamizadores de tipo cultural vinculados al contexto de reconstrucción de la democracia y de la paz internacional en el período de la Segunda posguerra (Klengel "El derecho"; Sapiro 89). La sistemática publicación de textos de Fidel Castro o Ernesto "Che" Guevara en la China revolucionaria, por el contrario, claramente, al orden político. Puesto que los contextos cambian, los condicionamientos que afectan la circulación internacional de literatura no son estáticos o trascendentes, de tal manera que el corpus acumulado de la literatura mundial-comprendida, según David Damrosch, por "[A]11 literary works that circulate beyond their culture of origin, either in translation or in their original language" (4)- se compone de elementos heterogéneos ligados a demandas históricas específicas y divergentes. En el contexto del actual diseño mundial, donde el capitalismo trasnacional opera como campo de acción, los factores hegemónicos que condicionan los flujos de literatura van a ser, fundamentalmente, del tipo económico (Sapiro 87; Locane).

A la luz de estos postulados teóricos, el objetivo de las siguientes páginas es someter a examen un caso de propagación internacional de literatura latinoamericana que hasta el momento no ha sido mayormente estudiado y que, según voy a proponer, obligaría a replantear algunos axiomas sobre los que se fundan los estudios dedicados a la circulación 
transatlántica de literatura latinoamericana, con el boom considerado habitualmente como su momento de apogeo. Un esquema, este último, que en sus trazos gruesos afirmaría que la literatura latinoamericana se dispara en Europa a partir de 1962 con la asignación del Premio Biblioteca Breve a Mario Vargas Llosa y que, por lo tanto, ese "descubrimiento" de la literatura latinoamericana tendría un epicentro en Barcelona-además del más clásico París-y que desde allí, a su vez, se propagaría hacia otros países europeos y, luego, hacia otras regiones del mundo. Este diseño - que sin duda privilegia indicadores de ventadebe ser al menos matizado si se examina la activa y prolífica función mediadora que desempeñaron, en el período de inmediata posguerra, exiliados de origen alemán que se establecieron en el subcontinente americano y que, en casos, retornaron a países de habla alemana una vez pacificada Europa y reestablecido el orden democrático en Alemania.

Como propone William Marling en su libro Gatekeepers: The Emergence of World Literature and the 1960s, los agentes que intervienen en la producción y promoción de literatura cobran en la escala internacional una importancia categórica ${ }^{1}$. Los traductores - de manera ejemplar Gregory Rabassa para el caso de Gabriel García Márquez- se imponen, así, como mediadores con una doble competencia cultural decisiva para el éxito en el terreno de la literatura mundial. El foco de este artículo se concentra en un actor concreto entendido como uno de estos importantes articuladores culturales cuya función y efecto, no obstante, todavía no han sido plenamente evaluados.

Albert Theile nació en Hörde, hoy un distrito de la ciudad de Dortmund, en 1904. En 1925 emprende un primer viaje hacia Grecia y Medio Oriente y poco tiempo después va a comenzar a colaborar, como periodista itinerante o una suerte de corresponsal informal, con la revista local Die Böttcherstrasse y también con periódicos de España y Francia. Entre 1932 y 1933 va a estudiar en Berlín Historia, Comunicación, Arte oriental y Filosofía y a continuación va a hacer un viaje que lo llevará hasta Japón y más tarde a Noruega, siempre vinculado a proyectos periodísticos y editoriales. En 1940, luego

1 También Venkat Mani, con su reciente Recoding World Literature: Libraries, Print Culture, and German's Pact with Books, "seek[s] to draw attention to the very large body of actors -beyond the author and the translator of a literary work- who determine a reader's access to literary works" (38). Y argumenta que "If a work of literature originates in a space beyond the immediate geolinguistic location of the reader, the number of actors increases exponentially. If the author and the reader were to be tentatively imagined in a producerconsumer relationship, there is also an entire set of mediators, crossing many institutions and media, who enable the distribution and circulation of a literary artifact for a worldwide readership" (38-39). A diferencia de lo que sucede en el nivel nacional o local, en el dominio de la literatura mundial la acción de mediadores con un doble capital cultural y social resulta insoslayable y decisiva, al punto de que estos actores deberían ser considerados coproductores del objeto literario mundial. 
de la invasión de Dinamarca y Noruega por parte de Alemania, y ya en la mira de la Geheime Staatspolizei, Theile emprende el camino del exilio, primero a Rusia, China e India y, luego, a Japón, donde ya contaba con una cierta red social de inserción, para pasar de allí, a fines de ese año, junto con un contingente de exiliados judíos, a Chile. Este momento, determinado por la evolución política de Alemania que lo había conducido al exilio, inaugura una etapa de su vida que recién acabaría en 1986 con su muerte en Suiza donde se había establecido a su retorno en 1952. Van a ser cuarenta y seis años de intensa actividad mediadora, bidireccional, entre América Latina y Alemania, documentada en un epistolario, actualmente disperso, que incluye, por ejemplo, comunicaciones con Thomas Mann para su publicación en Chile, con Gabriela Mistral para acordar colaboraciones y traducciones, o con Alfonso Reyes para impulsar desde Suiza y Noruega su candidatura al Premio Nobel (Ugalde Quintana).

En lo que sigue me voy a permitir cierto esquematismo y enumerar algunos de sus emprendimientos culturales concretos.

Entre 1943 y 1946, Albert Theile publicó en Chile, junto con Udo Rusker un semanario que, con un tiraje que alcanzó los 5000 ejemplares, pasaría a la historia como una de las publicaciones más importantes de exiliados alemanes: las Deutsche Blätter. Entre sus colaboradores, figuran, junto con el ya mencionado Thomas Mann, Stefan Seis, Günther Anders, Hermann Hesse o Carl G. Jung. Desde una posición liberal no partidaria -que más tarde se expresaría bajo la forma de una exaltación de Berlín occidental como "piedra de toque del mundo libre" (Theile, Berlín)-, la misión que se asignó la publicación fue, fundamental aunque sutilmente, de contrapropaganda. De ahí que el nombre del semanario fuera acompañado por una consigna que, acaso, no ha perdido vigencia: "Für ein europäisches Deutschland, gegen ein deutsches Europa" -"Por una Alemania europea, contra una Europa alemana"-.

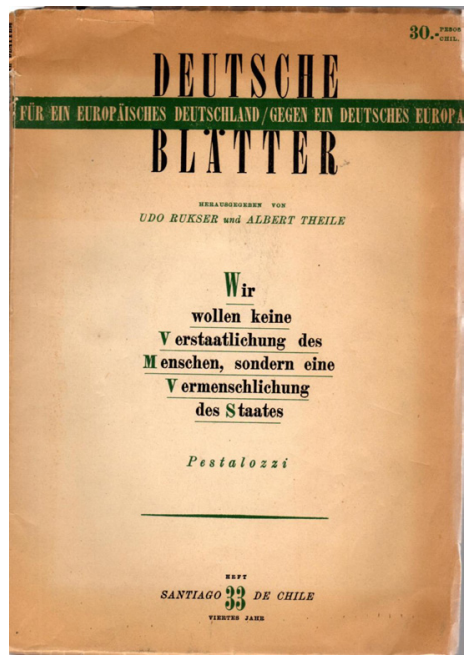

Deutsche Blätter, n. 33 
Pero en la publicación también tenía espacio la literatura y la poesía, y encontraron su lugar escritores españoles y latinoamericanos que, por este medio, por primera vez tendrían lectores de habla alemana: Ezequiel Martínez Estrada, Jorge Luis Borges ${ }^{2}$, Gabriela Mistral, Pablo Neruda, Yolanda Bedregal, Alfonso Reyes y Jorge Icaza, entre otros. Además, la publicación venía acompañada por un "Resumen castellano" destinado a establecer cierta comunicación con lectores hispanohablantes.

Pero es recién a su regreso a Europa que Theile comienza su intensa actividad de promoción y traducción de literatura latinoamericana. En 1955 aparece su libro en tres volúmenes ilustrados Die Kust der aussereuropäischen Völker (Hamburg: StandardVerlag), donde estudia y presenta expresiones artísticas no occidentales o de las regiones que -con una expresión hoy en boga- conforman el Sur global. La segunda parte del primer volumen está dedicada al arte precolombino y al arte colonial de América Latina. En los otros volúmenes queda plasmada de algún modo su experiencia previa en países de Medio Oriente y Asia.

También en 1955 aparece su antología de poesía latinoamericana titulada Schwan im Schatten: lateinamerikanische Lyrik von heute (München: Albert Langen-Georg Müller) a la que van a seguir otras antologías y selecciones traducidas en colaboración con su mujer, Gerda Theile, y algunos otros traductores. De 1956 es Unter dem Kreuz des Südens. Erzählungen aus Mittel-und Südamerika, aparecida -y el dato no es irrelevante- en la colección "Weltliteratur" de la editorial suiza Manesse; de 1958, la colección Gedichte (Darmstadt: Luchterhand), de Gabriela Mistral; de 1959, Bebendes Herz der Pampa. Dichtung der Gauchos (Zürich: Die Arche); y de 1962, Es tagt die Erde: Indianerdichtung aus dem südlichen Amerika y también Lateinamerika erzählt: Siebzehn Erzählungen (Hamburg: Fischer). De la mayoría de estas publicaciones va a haber reimpresiones y reediciones en diferentes editoriales de donde se deduce cuál es la aceptación e influencia que ellas pudieron tener en la recepción de habla alemana. Si en términos generales la clave costumbrista es ciertamente dominante, también corresponde señalar que fórmulas que se apartan de dicha clave encontraron en estas publicaciones su primera traducción y, en casos, también la única: "La forma de la espada", de Borges, por ejemplo, aparece traducido por el mismo Albert Theile en Unter dem Kreuz des Südens y "El guardagujas", de Juan José Arreola, por Gerda Theile en Lateinamerika erzählt ${ }^{3}$. Conviene destacar en

2 Esta temprana traducción o "Nacherzählung" del cuento de Jorge Luis Borges "Las ruinas circulares" (1944, nr. 8, pp. 23-25) es de Herta Landshoff y Paul Zech (Nitschack 5).

En su estudio sobre Ludwig Kunz como mediador cultural, Els Andringa comenta (95-96) un episodio extraído de su intercambio epistolar con Albert Theile que puede iluminar aspectos de cuál era, en el contexto de posguerra, cierta concepción de la literatura latinoamericana y cuál era el criterio de Theile. En agosto de 1951, Kunz le solicita a Theile que le envíe desde Chile una muestra de poesía latinoamericana para ser publicada en $D e$ Kim (1950-1955), la revista que él dirigía en Alemania. A tal solicitud, Theile responde con una traducción de Gabriela Mistral y una de Xavier Villaurrutia y, más tarde, con la propuesta de publicar una selección mayor, acompañada de fotografías, de Pablo Neruda. Kunz, no obstante, volvió a reiterar el pedido, pero con la aclaración de que lo que él esperaba publicar 
este punto que la actividad de difusión y traducción que lleva a cabo Theile comienza antes de que Borges recibiera en 1961 el Premio Formentor Internacional -compartido con Samuel Beckett- y de que un año más tarde Mario Vargas Llosa recibiera el Biblioteca Breve por La ciudad y los perros.

En 1960, Theile inaugura un proyecto paralelo no menos relevante: funda, como publicación de la editorial Übersee de Hamburgo, la revista Humboldt, que, actualmente patrocinada por el Goethe Institut, "configura y fomenta el diálogo cultural entre Alemania y América Latina, España y Portugal apelando a la figura de Alexander von Humboldt, quien, con su exploración del continente latinoamericano, sentó las bases de un vivo intercambio entre las naciones y se convirtió en símbolo de una estrecha vinculación entre Alemania, Europa y Latinoamérica" (Ebert) y donde, naturalmente, van a tener espacio de expresión numerosos escritores del mundo hispanohablante.

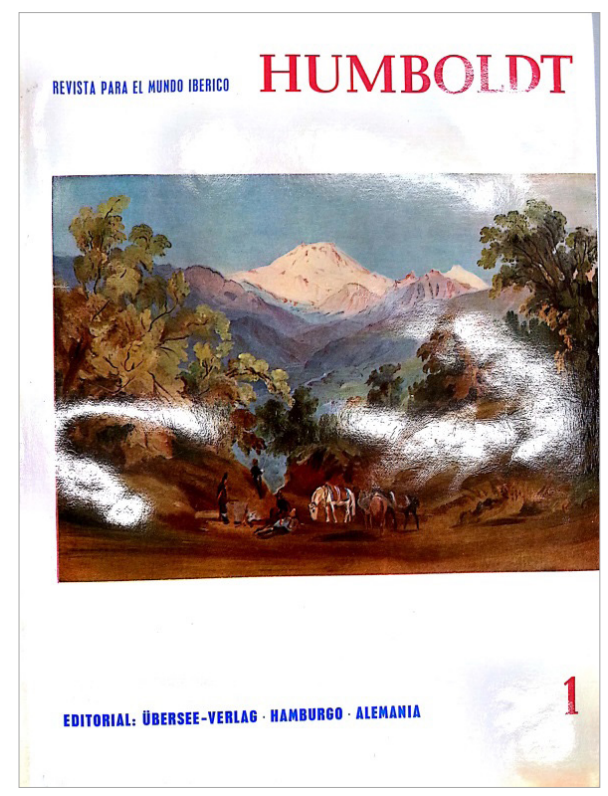

Humboldt, n. 1, 1960

Desde 1963, esta publicación se va a complementar con Fikrun wa Fann (Arte y pensamiento), también fundada por Theile, pero dedicada al mundo islámico.

era poesía anónima indígena. Esto último fue lo que, finalmente, apareció publicado en $D e$ Kim con colaboración de Theile. 
Como director de la revista Humboldt y en cooperación con el Iberoamerikanisches Institut de Berlín, Theile va a organizar dos grandes eventos que anteceden a los muchos que van a venir más adelante, ya en la órbita del boom, como pueden ser la Feria del Libro de Frankfurt de 1976 dedicada a América Latina o el Horizonte-Festival: Lateinamerika in Berlin de 1982. En 1962 tiene lugar en Berlín el Primer Coloquio de escritores iberoamericanos y alemanes, al que asisten, además de escritores alemanes y latinoamericanistas que, como Gustav Siebenmann, Anneliese Botond y Hans Magnus Erzensberger se van a ir consolidando progresivamente como importantes mediadores, un grupo no desdeñable de escritores latinoamericanos: Enrique Anderson Imbert, Héctor Murena, José María Arguedas, Alberto Baeza Flores, Alejandro Carrión, Rosario Castellanos, León de Greiff, Juan Rulfo y João Guimarães Rosa.

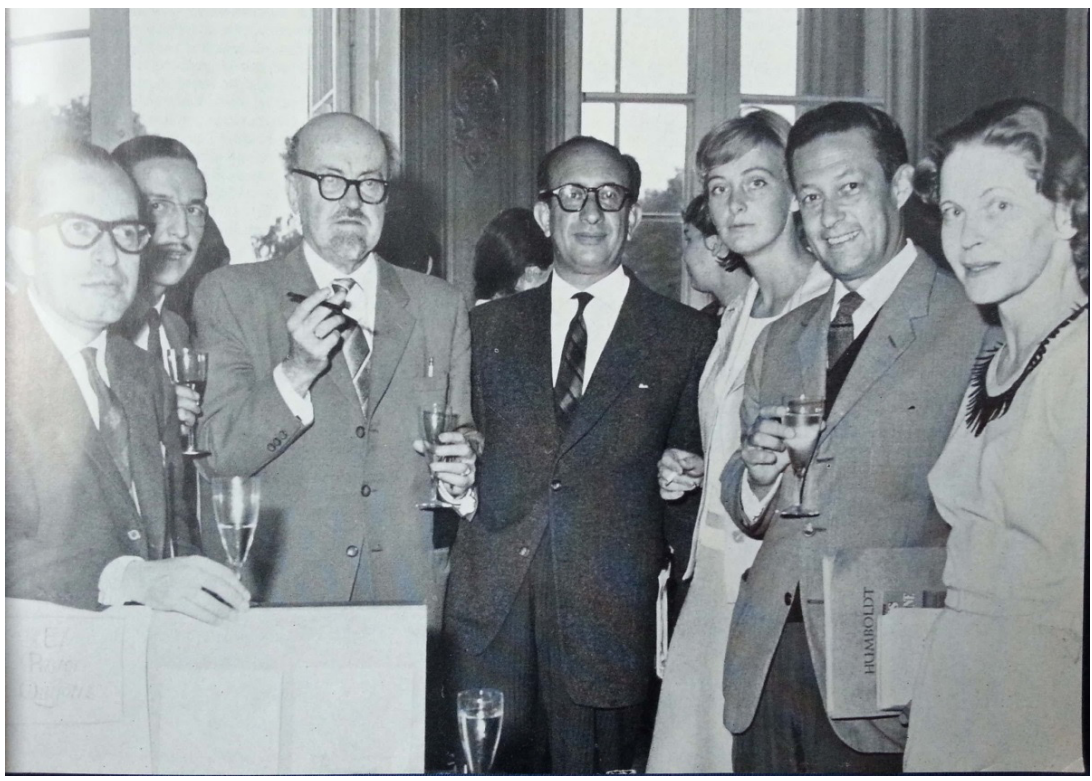

Primer Coloquio de escritores ibero-americanos y alemanes, Berlín 1962. Alejandro Carrión, Rafael Gutiérrez Girardot, León de Greiff, Alfredo Cardona Peña, Ingrid Bachér, Juan Liscano y Anneliese Botond (Theile, Primer 25)

Dos años después, el Segundo Coloquio convoca a Ciro Alegría, Miguel Ángel Asturias, Eduardo Mallea, Jorge Luis Borges, Julio Ramón Ribeiro, Augusto Roa Bastos y otra vez a João Guimarães Rosa. Nombres, todos estos, que, de por sí, comunican que el denominado boom de la literatura latinoamericana todavía no había hecho eclosión y que, aun así, en Alemania ya se estaba entretejiendo, al menos de manera incipiente, una plataforma de recepción que, con todo lo que se le puede cuestionar, le debe mucho a Albert Theile. 
Este rápido repaso de la trayectoria de mediación de Theile conduce a una serie de conclusiones que permite replantear, o al menos matizar, algunas de las afirmaciones más naturalizadas en los estudios dedicados a la circulación internacional de literatura latinoamericana.

A la luz de este caso, toma forma una historia alternativa que puede ser delineada como sigue. En los años 50, en Alemania coinciden, al menos, dos factores que van a favorecer la traducción y difusión de literatura latinoamericana. El primero es la posibilidad de retornar o establecer un diálogo productivo que desde ese momento tuvieron los intelectuales exiliados durante la hegemonía del nacionalsocialismo y la Segunda Guerra. Muchos de ellos, como Albert Theile, Udo Rusker, Anna Seghers, Mariana Frenk-Westheim (quien en 1958 traduce Pedro Páramo desde México), Erich Arendt (traductor temprano de Pablo Neruda y Nicolás Guillén), Ludwig Renn (que en 1948 publica en traducción los relatos mayas de Ermilo Abreu Gómez), Paul Zech (primer traductor de Borges; en 1952 publica la traducción de Huasipungo, de Jorge Icaza), Hans Platschek (traductor de Los pasos perdidos, de Alejo Carpentier, en 1958) y Curt Meyer-Clason (traductor, entre muchos otros, de Marco Denevi, Jorge Amado, Augusto Roa Bastos y João Guimarães Rosa) se convirtieron en activos mediadores, traductores y difusores culturales en ambas direcciones. O ligados por las circunstancias y sin que necesariamente existiera una motivación previa, estos intelectuales se transformaron en ese tipo de expertos con doble competencia cultural que, como condición necesaria, necesita la literatura para devenir mundial. El segundo factor es que en la coyuntura de posguerra, Alemania - antes que cualquier otro país- estaba obligada a construir un marco de democracia ampliada y entendimiento internacional ${ }^{4}$. Así, de hecho, quedó referido en la edición especial de la revista Humboldt dedicada al Primer Coloquio de Berlín. "Esta semana de convivencia" - se lee en la nota editorial- "ha permitido a nuestros invitados de la América Latina conocer más de cerca a esta Alemania resurgida de sus cenizas con un espíritu abierto a todos los progresos, a todos los intercambios y a todas las amistades, y que, sin olvidar los tesoros de su filosofía, de su ciencia y de su arte, favorece las más audaces iniciativas intelectuales de nuestra época" (Theile, Primer 4).

Impulsada por estas condiciones - derivadas del movimiento internacional (forzado) de personas, y que, por lo tanto, habría que ubicar, de acuerdo con Sapero, en el orden de lo social- comienza a delinearse una temprana propagación de literatura latinoamericana en los países de habla alemana. Antes se habían dado casos aislados e incipientes, como el del infatigable George Neuendorff -traductor de La vorágine (Leipzig: Hans Müller, 1934. Der Strudel: das Buch vom Kautschuksammler)-y su mujer Maria Schwauss, quien en los años 50 va a traducir, entre otros, a Ciro Alegría y Carlos Luis Fallas, pero con el retorno de los exiliados y la capitalización de las redes intelectuales que se habían gestado

$4 \quad$ Para un examen en profundidad de la coyuntura, aunque con foco en Francia, véase Klengel Die Rückeroberung. 
en los años anteriores, la traducción de literatura latinoamericana adquiere un carácter orgánico. Junto con las antologías de Theile ya mencionadas, habría que considerar que en los quince años que van desde el fin de la Guerra a 1960 aparecen obras individuales de Juan Rulfo (1958), Alejo Carpentier (1958), Jorge Luis Borges (1959), Miguel Ángel Asturias (1956), Pablo Neruda (1949), Nicolás Guillén (1952), Jacques Roumain (1947), Gabriela Mistral (1958), José Eustasio Rivera (1946), Rómulo Gallegos (1952), Ciro Alegría (1945), Enrique Larreta (1958), Jorge Icaza (1952), Elías Castelnuovo (1949), Jorge Amado (1946, 1954, 1958) y Ventura García Calderón (1956), entre otros.

Hay al menos dos rasgos que distinguen este importante flujo de literatura latinoamericana hacia el mundo germanohablante: el primero es que no se encuentra mediado por la industria editorial española; y el segundo, que anticipa el boom y los años 60 que, según propuso José Donoso en su Historia personal del “boom” y llegaría a instalarse en el sentido común, constituirían la primera y más importante instancia de "internacionalización" de la literatura latinoamericana. Los alemanes exiliados en América Latina, mediante el contacto directo con los sistemas culturales del subcontinente, se van a hacer con un capital lingüístico, cultural y social que les va a permitir prescindir de la mediación de España, esto implica que, en muchos casos, ellos mismos van a ser responsables de seleccionar y traducir la literatura que va a entrar en circulación en los países de habla alemana, lo que claramente contrasta con la posterior circulación vía Seix Barral/Carmen Balcells a partir de mediados de los años 60. En lo que respecta al proceso de internacionalización de la literatura latinoamericana que supone que su reconocimiento y difusión habría comenzado con el Premio Internacional Formentor a Borges en 1961 y el Biblioteca Breve a Mario Vargas Llosa en 1962 y que esto, a su vez, habría tenido un efecto retroactivo y disparado un "descubrimiento" de escritores de épocas anteriores, mi conclusión es que, así planteado, habría que desmentirlo. No solo porque desde el fin de la Guerra, gracias a mediadores "directos" como Albert Theile, la literatura latinoamericana empieza a estar presente en traducción en todos los países de habla alemana, sino también porque Borges ya había sido traducido al alemán, primero parcialmente en las Deutsche Blätter (1944) en Chile y en la antología de Theile Unter dem Kreuz de 1956 y, finalmente, con una selección de Ficciones y El aleph bajo el título Labyrinthe, en 1959, por quien se convertiría en su traductor oficial, Karl August Horst, y otros colaboradores.

De acá, entonces, se podría concluir que, lejos de ser imprescindible, como da a entender el fenómeno de boom, la mediación española, y más específicamente la de su industria cultural guiada naturalmente por sus intereses, entre América Latina y el resto del mundo puede ser sorteada gracias a la actividad de otros mediadores con suficiente capital cultural como el que acumularon los exiliados alemanes durante su estancia en el subcontinente. Otra conclusión que se extrae del recorrido que he propuesto es que es necesario rever la historia de la literatura latinoamericana según fue elaborada por los mismos protagonistas del boom y que, básicamente, afirma que antes de su generación no había mucho que mereciera ser traducido y menos que efectivamente lo hubo. El caso de Theile y las traducciones de Borges al alemán sugieren que el "descubrimiento" de este último tuvo lugar primero en Chile, que desde allí "viajó" a Suiza con Theile para aparecer en su antología de 1956 y luego ser traducido "completo" por Horst. Dos años 
más tarde recibiría el Premio Internacional Formentor, acaso alentado por la traducción en Suiza y Alemania -sin desatender, por supuesto, que Labyrinthes, de Roger Caillois, es de 1953-, y uno más tarde, recién en 1962 -ahora sí después del Formentor- llegaría la traducción al inglés de Labyrinths, por parte de Norman Thomas di Giovanni.

Este sustancial rediseño de la historia de la literatura latinoamericana en el mundo germanohablante conduce, a su vez, a revisar el supuesto que le asigna a la editorial Suhrkamp un lugar protagónico indiscutido. En efecto, desde 1974 Suhrkamp, bajo el asesoramiento de Michi Strausfeld, emprende un destacable programa de actualización en lo que respecta a literatura latinoamericana (Strausfeld). Muchos escritores centrales de la tradición latinoamericana reciente, como Juan Carlos Onetti, Manuel Puig o Guillermo Cabrera Infante, van a ser traducidos por primera vez al alemán bajo auspicio de este programa y publicados en los años 70 en Suhrkamp, lo mismo que, por ejemplo, Rayuela, de Julio Cortázar, en 1981. No obstante, hasta ese momento -que, cabría inferir, asimila tardíamente el espíritu del boom-, la literatura latinoamericana había estado presente -y seguiría estándolo- en otras editoriales como Aufbau Verlag, Manesse, Luchterhand, Rowohlt, Kiepenheuer y Witsch, Hanser y, de manera fundamental, en la importante Volk y Welt (Kirsten). De Cortázar, por ejemplo, van a aparecer títulos en 1963, 1965 y 1966 en Luchterhand, y recién en 1976 en Suhrkamp. En esta misma editorial ya en los años 50, y por influjo de exiliados, entre los que cuenta Theile, van a aparecer algunas de las primeras traducciones de Pablo Neruda, de Gabriela Mistral y de Rómulo Gallegos. Jorge Amado, Miguel Ángel Asturias, Alejo Carpentier, José María Arguedas, Carlos Fuentes y Mario Vargas Llosa, por su parte y entre otros, al igual que Neruda, van a ir apareciendo regularmente, desde fines de los años 40 en adelante, en la editorial de la República Democrática Alemana Volk y Welt. Por otra lado, y como evidencia de que la atención de Suhrkamp a la literatura latinoamericana fue un fenómeno coyuntural ligado a intereses comerciales y al reconocimiento internacional de los escritores del boom, "el programa empieza a estancarse desde el año 2000" (Müller 88).

En su estudio sobre antologías, Vera Gerling destaca la importancia que tuvo Suhrkamp como promotor mediante la publicación de antologías de literatura latinoamericana en alemán; añade, no obstante, que de ninguna manera corresponde atribuirle un papel pionero ni especialmente sobresaliente en comparación con el de otras editoriales ${ }^{5}$. Esta observación, que se limita a lo que atañe a antologías, en vista de lo aquí expuesto, debe ser reformulado en términos más generales y con la aclaración de que fueron los exiliados alemanes en América Latina, como Albert Theile, quienes ya a fines de los años 40 -con todas las naturales deficiencias que se pueden identificar, como puede ser cierta atracción por la miseria y la opresión (Kirsten 162)- iniciaron un tráfico relativamente regular y orgánico de literaturas latinoamericanas hacia el mundo germanohablante.

\footnotetext{
"Somit zeigt sich, dass der als Promotor der lateinamerikanischen Literatur bekannte Verlag Suhrkamp hier zwar ein wenig öfter vorkommt als andere. Jedoch muss zugleich unterstrichen werden, dass gerade die Pionierrolle bei der Bekanntmachung von Literatur über diesen Typus von Anthologien anderen Verlagen zukommt” (78).
} 


\section{BIBLIOGRAFÍA}

Andringa, Els. "Kontinuität und Wandel. Kunz' Netzwerke vor und nach dem Krieg”. Avantgarde \& Exil-Ludwig Kunz als Kulturvermittler. Autor und Vermittler zwischen den Künsten und Sprachen. Ed. Els Andringa. Zürich: LIT, 2017. 63-96.

Damrosch, David. What is World Literature? Princeton: Princeton University Press, 2003.

Donoso, José. Historia personal del “boom”. Barcelona: Anagrama, 1972.

Ebert, Johannes. "Editorial”. Humboldt (2013). Web. 25 dic. $2017<$ http://www.goethe.de/ wis/bib/prj/hmb/the/159/es11280315.htm>

Estermann, Alfred. "Geist und Geld und Grenzüberschreitung. Die Böttcherstrasse, eine 'Weltzeitschrift'”. Buchkulturen: Beiträge zur Geschichte der Literaturvermittlung. Festschrift für Reinhard Wittmann. Eds. Monika Estermann, Ernst Fischer y Ute Schneider. Wiesbaden: Harrassowitz Verlag, 2005. 445-485.

Gerling, Vera Elisabeth. Lateinamerika: so fern und doch so nah?: Übersetzungsanthologien und Kulturvermittlung. Tübingen: Narr, 2004.

Kirsten, Jens. "Bücher aus Lateinamerika". Fenster zur Welt. Eine Geschichte des DDRVerlages Volk und Welt. Eds. Simone Bark y Siegfried Lokatis. Berlin: Ch. Links Verlag, 2005. 162-168.

Klengel, Susanne. Die Rückeroberung der Kultur: lateinamerikanische Intellektuelle und das Europa der Nachkriegsjahre (1945-1952). Würzburg: Königshausen \& Neumann, 2011.

"El derecho a la literatura (mundial y traducida). Sobre el sueño translatológico de la UNESCO". Re-mapping World Literature. Writing, Book Markets, and Epistemologies between Latin America and the Global South. Eds. Gesine Müller, Jorge J. Locane y Benjamin Loy. Berlin: De Gruyter, 2018. 131-155.

Locane, Jorge J. De la literatura latinoamericana a la literatura latinoamericana mundial: condiciones materiales, procesos y actores. Berlin: De Gruyter, 2018 (inédito).

Mani, Venkat. Recoding World Literature: Libraries, Print Culture, and Germany's Pact with Books. New York: Oxford University Press, 2017.

Marling, William. Gatekeepers: The Emergence of World Literature and the 1960s. New York: Oxford University Press, 2016.

Müller, Gesine. "¿Literatura mundial o literaturas del mundo? Un estudio del caso de las letras latinoamericanas en la editorial Suhrkamp". América Latina y la literatura mundial: mercado editorial, redes globales y la invención de un continente. Eds. Gesine Müller y Dunia Gras Miravet. Madrid/Frankfurt am Main: Iberoamericana/Vervuert, 2015. 81-95.

Nitschack, Horst. "Las Deutsche Blätter (Hojas alemanas) en Chile (1943-1946): una revista alemana del exilio en los márgenes de la historia literaria”. Revista Chilena de Literatura, nr. 77 (2010): 1-9. Web. 25 de dic. $2017<$ http://www.revistaliteratura.uchile.cl/index. $\mathrm{php} / \mathrm{RCL} /$ article/view/9133>

Sapiro, Gisèle. "How Do Literary Works Cross Borders (or Not)? A Sociological Approach to World Literature". Journal of World Literature, nr. 1 (2016): 81-96.

Schumacher, Martin: "Wir wollten als Deutsche nicht abseits stehen" - die Herausgeber der 'Deutschen Blätter' in Santiago de Chile Udo Rukser (1892-1971) und Albert Theile 
(1904-1986)". Gesichter der Demokratie. Porträts zur deutschen Zeitgeschichte. Eds. Bastian Hein, Manfred Kittel y Horst Möller. München: Oldenbourg Wissenschaftsverlag, 2015. 89-108.

Strausfeld, Michi. “1974-2004: 30 Jahre Lateinamerika im Suhrkamp/Insel Verlag”. Lateinamerikanische Literatur im deutschsprachigen Raum. Eds. Friedhelm SchmidtWelle y Diana von Römer. Frankfurt am Main: Vervuert, 2007. 159-171.

Theile, Albert (dir.). Berlín, piedra de toque del mundo libre: textos y documentos. Hamburg: Übersee-Verlag, 1959.

(dir). Humboldt: primer coloquio de escritores ibero-americanos y alemanes. Berlín 1962. Hamburg: Übersee-Verlag, 1963.

Ugalde Quintana, Sergio (ed.). Un cierto encanto goethiano: correspondencia alemana de Alfonso Reyes (1914-1959). México: El Colegio de México, 2013.

Vander Heide, Ralph P. German Leaves. Opposing Nazi Cannons with Words. Bloomington: Xlibris Corp, 2012. 